\title{
Internship training adequately prepares South African medical graduates for community service - with exceptions
} \author{
N M Nkwanyana, ${ }^{3}$ BSc Statistics and Applied Maths, BSc Hons Statistics, MSc Statistics \\ ${ }^{1}$ Department of Family Medicine, University of KwaZulu-Natal, Durban, South Africa \\ ${ }^{2}$ Primary Healthcare Directorate, Faculty of Health Sciences, University of Cape Town, South Africa \\ ${ }^{3}$ Department of Public Health Medicine, University of KwaZulu-Natal, Durban, South Africa
}

T C Nkabinde, ${ }^{1} \mathrm{MB}$ ChB; A Ross, ${ }^{1} \mathrm{MB}$ ChB, DCh (SA), MMed (Fam.Med), FCFP (SA); S Reid, ${ }^{2}$ BSc Med, MB ChB, MFamMed, PhD;

Corresponding author: T C Nkabinde (dr.nkabinde@gmail.com)

Background. The 2-year internship period for medical graduates began in South Africa in 2005 and has never been formally evaluated. Objective. This study assessed the perceptions of community service medical officers (COSMOs) working at district hospitals (DHs) in KwaZulu-Natal (KZN) to determine whether the 2-year internship programme had adequately prepared them for community service (CS). Method. A cross-sectional descriptive study was conducted regarding the perceptions of COSMOs working at 22 district hospitals in KZN. Data were collected in July 2012, using a questionnaire based on the core skills and knowledge detailed in the Health Professions Council of South Africa intern log book. All eight domains were self-assessed and a score of 4 out of 5 indicated an ability to work independently. Results. Of the COSMOs, 78\% (60 out of 89) completed the questionnaire. Most felt well-prepared for CS in all disciplines, but critical gaps in knowledge and skills were identified in paediatrics, orthopaedics, anaesthetics and obstetrics. In addition, $75 \%$ of respondents ( 45 out of 60) expressed a need for additional training in the disciplines of ear, nose and throat (ENT), urology, ophthalmology and dermatology. Conclusion. The 2-year internship has provided the basis for independent medical practice in DHs. However, certain critical skill gaps need urgent attention, particularly in obstetrics and anaesthesia. Areas of weakness in ENT, urology, ophthalmology and dermatology could be addressed by including these specialities as a compulsory rotation in surgery, medicine or family medicine during internship training.

S Afr Med J 2013;103(12):930-934. DOI:10.7196/SAMJ.6702

口739

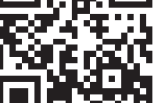
In $1950,{ }^{[1,2]}$ South Africa (SA) introduced a 1-year internship that let newly qualified doctors complement their academic training with practical application. This programme was not uniform for all graduates, did not enforce holistic exposure, focused on specialised training in secondary and tertiary hospitals, and did not require proof of competence at the end of the training period. ${ }^{[1]}$

Following democratic elections in 1994, the government adopted a primary healthcare approach to provide primary-level healthcare to all South Africans. ${ }^{[3]}$ The Ministerial Committee on Human Resource Development recommended that post-graduate vocational training (PGVT), with appropriate supervision, be made compulsory postinternship. ${ }^{[4]}$ In July 1996, the interim South African Medical and Dental Council approved the introduction of PGVT for doctors from January 1998. ${ }^{[5]}$ The National Department of Health (DoH) simultaneously proposed a 2-year compulsory community service (CS) period for all medical graduates after internship, to meet the health needs of rural communities. In 1997, the Medical and Dental Education Committee and Technical Group of the Health Professions Council of South Africa (HPCSA) recommended a 2-year structured internship programme to ensure interns' competencies and skills in all domains. ${ }^{[1,2]}$

In 1998, PGVT was replaced with one year of compulsory CS post-internship, ${ }^{[6]}$ via the Health Professions Amendment Act. ${ }^{[7,8]}$ CS primarily aimed to improve the supply of professional health personnel in under-served areas, ${ }^{[4]}$ and improve health service provision to all South Africans. As the programme consists of 'service not training, ${ }^{\text {'[4,7] }}$ COSMOs are allocated according to healthcare needs as determined by the DoH, rather than available supervision. A 1999 study showed that COSMOs felt they were making a difference, though supervision and support were sometimes felt to be poor. ${ }^{[4]}$ Senior supervision of
COSMOs has been proven lacking, particularly in rural areas where COSMOs are expected to practise basic medical skills independently, including emergency skills, and make triage decisions. ${ }^{[7,9]}$

With the introduction of compulsory CS without adequate supervision, academics in several disciplines ${ }^{[2]}$ expressed concern about the effectiveness of training during the 1-year internship. There was concern about the practical competence of post-internship doctors in orthopaedics, anaesthetics and obstetrics. ${ }^{[10,11]}$ Clearly, the Medical and Dental Education Committee needed to review the programme to determine whether it achieved the goals of internship training and whether graduates obtained hands-on experience under supervision as preparation for independent medical practice. ${ }^{[2]}$ In 2005 a 2-year internship programme was implemented in stages for graduates from the universities of the Free State and the Transkei, with graduates from all other medical schools starting internship in 2006. ${ }^{[10]}$ This programme was carefully structured. All training hospitals were accredited by inspectors from the internship subcommittee of the HPCSA. Hospitals were required to provide supervised, experiential internship training in paediatrics, surgery, obstetrics, internal medicine and family medicine/ mental health for 4 months each, and in anaesthetics and orthopaedics for 2 months each. A detailed intern logbook ensured a comprehensive skills and knowledge base was 'signed off' in each domain.

In 2008 Jaschinski and De Villiers ${ }^{[12]}$ reviewed factors influencing the development of practical skills for interns working in regional hospitals in the Western Cape, and concluded that the combination of university training and internship, with sufficient support and supervision, adequately prepared junior doctors for independent practice during CS. However, several specialists feel inadequate time is allocated to their domains, and the intern subcommittee identified a lack of exposure to urology, ENT, ophthalmology and dermatology 
(personal communication - Professor Emeritus A Malan (UCT)). To date, the new 2-year internship programme has never been evaluated to determine whether it is providing appropriate skills training for CS.

This study aimed to assess how COSMOs, who had been working at district hospitals (DHs) in KwaZulu-Natal (KZN) for 6 months, perceived the adequacy of their 2-year internship training programme in preparing them to manage common problems.

\section{Method}

This was a cross-sectional descriptive study. The target population was all 1250 COSMOs in SA who completed their internship in 2011. For 2012, the DoH allocated 152 COSMOs to KZN, of whom 89 were assigned to $35 \mathrm{DHs}$. This study aimed to sample all 89 , focusing on DHs since the widest scope of medical practice occurs at this level. The authors assumed that the 2-year internship programme had prepared these COSMOs to function independently at $\mathrm{DH}$ level, with minimal supervision.

In July 2012, the principal investigator (TCN) travelled to 22 of the $35 \mathrm{DHs}$ to administer the questionnaire to each COSMO. COSMOs on duty at the time completed the questionnaire independently and returned it in a sealed envelope. Those not available at the time of data collection or unwilling to participate were excluded from the study. The questionnaire was developed by the authors from the knowledge and skills list in the intern logbook. It was piloted among 10 medical officers who had completed their CS in 2011, to ensure that the questions were clear and unambiguous. Each domain contained a list of 8 to 10 core skills and knowledge, in which the COSMOs were asked to score their perceived competence on entry to CS on a Likert scale of 1 to 5 (see Table 1). Respondents were also asked to give additional comments after completing questions on each domain.

A score $\geq 4$ was considered to indicate adequate knowledge and skills and the ability to practise independently. A score $<4$ suggested the need for the area to be addressed during internship training. Data were captured onto an Excel spreadsheet and imported into SPSS version 21 software for analysis. A mean score was calculated for each knowledge and skill question, and all mean scores were added together and divided by the number of questions to give an overall score for each domain. The reliability of the scores was measured using Cronbach's $a$. Ethical permission was received from the University of KwaZulu-Natal (UKZN) Biomedical Research Ethics Committee. Permission to do the study was obtained from the 10 district health managers in KZN and their hospital management and the KZN provincial DoH. Informed consent was obtained from each respondent.

\section{Results}

Out of a possible $35 \mathrm{DHs}, 22$ were visited. Of the hospitals not visited, 4 had only one COSMO and were difficult to reach, and at 9 permission had not been obtained from the hospital management at the time of the planned visit. Out of the 89 COSMOs, $67.4 \%$ (60) completed the questionnaire, of whom $56 \%$ were female (34/60) and $44 \%$ male (26/60). The average age was 26.4 years (range $24-37$ years). Of the respondents, $56 \%(34 / 60)$ had studied at UKZN, and the balance at the universities of Stellenbosch (2), the Witwatersrand (6), Cape Town (5), Pretoria (3), and the Free State (1); Walter Sisulu University (4), the Medical University of Southern Africa (4) and outside of SA (1). Internship had been completed in 20 different hospitals in SA, with the majority training in KZN (11/20) and the rest in Gauteng (4/20), Mpumalanga (2/20) and Limpopo, the Eastern Cape and the Western Cape (1/20 in each instance). There was no statistical difference in the knowledge and skill levels of those who trained in a tertiary level hospital $(22 \%(13 / 60))$ compared with those who trained in a regional level hospital $(78 \%(47 / 60))$. Overall, in terms of preparedness for CS, internship was rated good by $63 \%$ $(38 / 60)$ and excellent by $15 \%$ (9/60), as shown in Fig. 1.

Most of the domains had an overall mean for knowledge and skills $>4$, except for surgical and orthopaedic skills, and anaesthetic and obstetrics knowledge and skills. No domain showed a large discrepancy between knowledge scores and skills scores. (Table 2 (abridged). The unabridged table is available online at http://www. samj.org.za. All scores have a Cronbach's $\alpha>0.7$, signifying reliability.

COSMOs expressed a need for further training in gynaecological ultrasonography, more theatre time for managing ectopic pregnancies and uncomplicated appendectomies, and in the reading of electrocardiograms (ECGs), insertion of a central venous pressure (CVP) line and managing rape survivors. While $75 \%(45 / 60)$ felt that additional training in urology, ENT, ophthalmology and dermatology was needed, 71.6\% (43/60) indicated this should be incorporated into existing rotations, without extending the internship period. None expressed a need for additional training in mental health.

\section{Discussion}

SA's 2-year internship programme has not been formally evaluated before. Regular evaluations are important, with Prinsloo ${ }^{[10]}$ suggesting that the programme's success should be measured by the competency of the COSMOs entering the system. Overall, 78\% (47/60) of

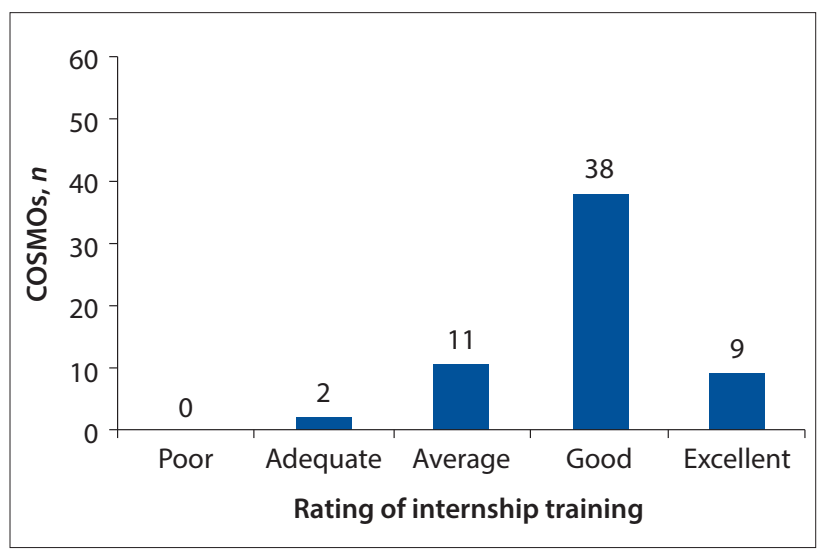

Fig. 1. Rating of internship in respect to overall preparedness for community service.

Table 1. Likert scale used to assess the respondents' perceptions of their skills and knowledge

\begin{tabular}{lll}
\hline Ranking & Knowledge & Skills \\
\hline 1 (Poor) & Know nothing & No skill at all \\
2 (Fair) & Know something, no experience & Some skill, no experience \\
3 (Average) & Some experience, still require supervision & Some experience, requires supervision \\
4 (Good) & Able to practise independently & Able to practise independently \\
5 (Excellent) & Able to teach someone else & Able to teach someone else
\end{tabular}


respondents rated their internship as good to excellent in preparing them for CS. As the main aim of CS is 'to ensure improved provision of health services to all the citizens of our country,, ${ }^{[4]}$ it is encouraging that COSMOs rate themselves as knowledgeable and competent to manage common medical and paediatric conditions seen at DHs. Most domains, except for surgical and orthopaedic skills, and anaesthetic and obstetrics knowledge and skills, had an overall mean for knowledge and skills $>4$. However, COSMOs identified a number of essential knowledge and skills entities in each domain that they felt they lacked at the end of their internship. Many of these are critical emergency skills, required when faced with an unstable patient in the hospital or casualty. The lack of confidence in certain anaesthetic and obstetric skills could make a difference between life and death in an emergency.

Overall, internal medicine scored highest in knowledge mean score and second highest in skills mean score. As internal medicine is the foundation of practice in medicine, this is encouraging. Respondents expressed a lack of knowledge and skills in managing patients presenting with malaria, arrhythmias and acute coronary syndrome. It is important that these be adequately covered in the internship programme.

Paediatrics was rated second in skills and third in knowledge. It is concerning that COSMOs expressed a lack of knowledge and skills regarding managing children on antiretroviral (ART) therapy, since HIV/AIDS has had a major impact on infant and child mortality rates in SA. A large number of paediatric HIV patients are seen at DHs. ${ }^{[13]}$ A rotation through the ART clinic should become compulsory as part of either family medicine or paediatrics training during internship. It is not clear when or if interns are formally exposed to HIV-positive children already on ART or those children who need to be initiated on ART, and this needs further study.

Family medicine scored second in knowledge and third in skills, with respondents confident in their ability to manage tuberculosis (TB) and HIV. This is encouraging as TB is the leading cause of death in SA and the most prevalent opportunistic infection in HIV-infected patients. ${ }^{[14]}$ Weaknesses were identified as the ability to manage undifferentiated conditions (a skill at the very heart of family medicine), medico-legal issues including dealing with rape survivors, the management of red eye, and the use of the ophthalmoscope. With the high rate of violence against women, ${ }^{[15]}$ it is essential that all practitioners are competent in assessing and treating victims and able to collect medico-legal evidence without compromising the chain of evidence.

Mental health scored well in knowledge and skills, with only the management of extrapyramidal side effects of antipsychotics being identified as an area of weakness. None of the respondents expressed a need for additional time or training in mental health.

Respondents felt unable to independently perform the urological procedures of suprapubic catheterisation, management of epididymoorchitis, and testicular torsion. They also cited a lack of knowledge and skills in managing patients with burns, particularly full-thickness burns requiring grafting. However, management of these patients is seldom an emergency, and COSMOs can request help or refer these patients as necessary. In orthopaedics, dislocation of major joints (hip and elbow) and management of extensor tendon injuries were identified as areas where knowledge and skills were lacking. While these injuries should be recognised, even in very remote $\mathrm{DHs}$, it is probably appropriate that they be referred to higher levels of care.

The 1998 National Confidential Enquiry into Maternal Deaths highlighted a lack of skills which was resulting in maternal deaths. In 2001, the National DoH set up a task team to assess the skills and competences of interns and junior doctors. This task team identified weaknesses in emergency procedures, in particular caesarian sections, anaesthesia and resuscitation skills. ${ }^{[16]}$ This study confirms that these areas still need attention. Although COSMOs feel competent to give a spinal anaesthetic, associated emergencies and their correct handling, all scored $<4$. Spinal anaesthetic, while recommended by the confidential inquiry into maternal deaths as being the preferred method of anaesthesia for most caesarean sections, ${ }^{[17]}$ is only safe if complications can be managed. In 2008 Lamacraft $^{[18]}$ studied the training and experience of doctors administering obstetric anaesthesia in Free State level 1 and 2 hospitals, and recommended that COSMOs should be supervised when performing obstetric anaesthesia because of limited exposure and experience. Clearly, the 2-month exposure to anaesthetics during the 2 -year internship does not equip COSMOs to practise independently. ${ }^{[2]}$

In obstetrics, COSMOs felt knowledgeable and competent to manage normal deliveries, interpret partograms and surgically manage incomplete miscarriages. However, they expressed a lack of knowledge and skills in managing emergencies in the labour ward (shoulder dystocia, antepartum haemorrhage, and cord prolapse). The 2005-2007 Saving Mothers Report highlighted obstetric haemorrhage (antepartum and postpartum) and complications of hypertension as 2 of 5 persistent major causes of maternal death. ${ }^{[19]}$ The Essential Steps in the Management of Obstetric Emergencies (ESMOE) programme, recommended as part of internship training at every training hospital, should address any lack of knowledge. Emergency skills, however, can only be honed through practice-under-supervision, yet in some intern programmes, interns do not spend time in the labour ward where such skills can be acquired (personal communication, Dr M Saba, Gauteng Department of Health). One of the major operations performed in a DH is a caesarean section and COSMOs reported inadequate experience in dealing with associated complications, such as uncontrollable haemorrhage, independently confirming the findings of the 2001 report. ${ }^{[17]}$ It is concerning that the skills to manage obstetric emergencies have not improved over the last 11 years, despite maternal and child health being a national priority.

COSMOs identified deficiencies in knowledge and training in ENT, ophthalmology, dermatology and urology, as seen in mean scores $<4$ for fundoscopy, management of red eye and urological conditions (Table 2). While acknowledging the need for more training, COSMOs believe this should be incorporated into existing domains, as a compulsory rotation in urology and ENT during surgery, and ophthalmology and dermatology during medicine or family medicine. Extra skills training required included managing burns, doing split skin grafts, the use of ketamine and regional anaesthetics and the use of obstetric ultrasound.

\section{Study limitations}

This study was limited to COSMOs working in DHs in KZN. Those working at regional hospitals or community health centres might have a different perception of the internship programme. The findings are based on reported rather than objective or observed competence, and self-reporting may introduce bias. Notably, all COSMOs had been deemed competent in a range of skills and knowledge, as shown in the $\log$ books signed off at the end of their internship. This study does not attempt to validate COSMOs' perceptions of their skills and knowledge.

\section{Conclusion}

The current 2-year internship programme lets young health professionals acquire the knowledge and skills needed to practise independently at a $\mathrm{DH}$, thus ensuring better health service provision to all South Africans. It is encouraging to note that the respondents are, in general, satisfied with the broad training provided. However, the specific gaps identified need to be addressed. Urology, ENT, ophthalmology and dermatology need to be incorporated into the internship programme, as many common conditions involving these 
Table 2 (abridged). The mean scores for skills and knowledge in each domain

\begin{tabular}{|c|c|c|c|c|c|}
\hline \multirow[b]{2}{*}{ Domain } & \multirow[b]{2}{*}{ Area } & \multicolumn{2}{|c|}{ Knowledge } & \multicolumn{2}{|c|}{ Skill } \\
\hline & & Mean & Range & Mean & Range \\
\hline \multirow[t]{8}{*}{ Internal medicine } & Overall mean score & 4.29 & & 4.16 & \\
\hline & Manage acute confusional state & 4.20 & $3-5$ & 3.98 & $2-5$ \\
\hline & CVP insertion & 4.15 & $2-5$ & 3.92 & $2-5$ \\
\hline & Manage common dermatological conditions & 4.08 & $2-5$ & 3.92 & $2-5$ \\
\hline & Manage acute coronary syndrome & 3.95 & $2-5$ & 3.73 & $2-5$ \\
\hline & Manage bleeding disorders & 3.88 & $2-5$ & 3.68 & $2-5$ \\
\hline & Manage malaria & 3.85 & $1-5$ & 3.65 & $1-5$ \\
\hline & Manage cardiovascular arrhythmia & 3.75 & $2-5$ & 3.47 & $2-5$ \\
\hline \multirow[t]{4}{*}{ Paediatrics } & Overall mean score & 4.25 & & 4.17 & \\
\hline & Paediatric resuscitation/intubation & 3.88 & $1-5$ & 3.62 & $1-5$ \\
\hline & Paediatric HIV treatment regimen & 3.82 & $1-5$ & 3.70 & $1-5$ \\
\hline & Initiating and monitoring child on ARV & 3.77 & $1-5$ & 3.68 & $1-5$ \\
\hline \multirow[t]{5}{*}{ Family medicine } & Overall mean score & 4.26 & & 4.15 & \\
\hline & Performing fundoscopy & 3.90 & $1-5$ & 3.68 & $1-5$ \\
\hline & Manage undifferentiated problems & 3.85 & $2-5$ & 3.67 & $2-5$ \\
\hline & Manage acute red eye & 3.83 & $2-5$ & 3.72 & $2-5$ \\
\hline & Manage a rape survivor and collect of evidence & 3.55 & $1-5$ & 3.17 & $1-5$ \\
\hline \multirow[t]{3}{*}{ Mental health } & Overall mean score & 4.24 & & 4.11 & \\
\hline & Manage bipolar disorder & 4.10 & $2-5$ & 3.97 & $2-5$ \\
\hline & Manage extra-pyramidal side-effects of antipsychotics & 4.05 & $3-5$ & 3.87 & $2-5$ \\
\hline \multirow[t]{12}{*}{ Surgery } & Overall mean score & 4.11 & & 3.94 & \\
\hline & Remove foreign body from ear & 4.17 & $2-5$ & 4.00 & $1-5$ \\
\hline & Perform circumcision & & & 3.98 & $1-5$ \\
\hline & Minor surgical procedure - excision of lumps/lymph nodes & 4.12 & $2-5$ & 3.93 & $1-5$ \\
\hline & Transportation of a critically ill patient & 4.02 & $2-5$ & 3.88 & $1-5$ \\
\hline & Manage snake bites & 3.98 & $2-5$ & 3.82 & $1-5$ \\
\hline & Insertion of a suprapubic catheter & 3.72 & $2-5$ & 3.30 & $1-5$ \\
\hline & Manage peripheral vascular injuries & 3.67 & $2-5$ & 3.47 & $1-5$ \\
\hline & Removal of foreign body from eye & 3.67 & $1-5$ & 3.35 & $1-5$ \\
\hline & Manage epididymo-orchitis & 3.53 & $1-5$ & 3.32 & $1-5$ \\
\hline & Surgical management of acute testicular torsion & 3.50 & $2-5$ & 3.03 & $1-5$ \\
\hline & Split skin graft for full-thickness burns & 2.93 & $1-5$ & 2.60 & $1-5$ \\
\hline \multirow[t]{8}{*}{ Orthopaedics } & Overall mean score & 4.04 & & 3.86 & \\
\hline & Manage wrist fractures & 4.13 & $2-5$ & 3.97 & $2-5$ \\
\hline & Manage finger dislocations & 3.98 & $2-5$ & 3.78 & $1-5$ \\
\hline & Appropriate review period according to age and type of injury & 3.92 & $2-5$ & 3.75 & $2-5$ \\
\hline & Manage acute spinal and pelvic injuries & 3.80 & $1-5$ & 3.55 & $1-5$ \\
\hline & Manage hip dislocations & 3.77 & $1-5$ & 3.43 & $1-5$ \\
\hline & Manage elbow dislocation & 3.70 & $1-5$ & 3.52 & $1-5$ \\
\hline & Manage extensor tendon injuries in upper limbs & 3.63 & $1-5$ & 3.45 & $1-5$ \\
\hline \multirow[t]{5}{*}{ Anaesthetics } & Overall mean score & 3.85 & & 3.92 & \\
\hline & Peri-operative fluid management & 3.98 & $2-5$ & 3.93 & $2-5$ \\
\hline & Use of ketamine & 3.97 & $2-5$ & 3.95 & $2-5$ \\
\hline & Analgesics and narcotics & 3.90 & $2-5$ & 3.82 & $2-5$ \\
\hline & Comfortable using emergency drugs in spinal anaesthesia & 3.83 & $2-5$ & 3.82 & $\begin{array}{l}2-5 \\
\text { ntinue }\end{array}$ \\
\hline
\end{tabular}


Table 2 (continued). The mean scores for skills and knowledge in each domain

\begin{tabular}{|c|c|c|c|c|c|}
\hline \multirow[b]{2}{*}{ Domain } & \multirow[b]{2}{*}{ Area } & \multicolumn{2}{|c|}{ Knowledge } & \multicolumn{2}{|c|}{ Skill } \\
\hline & & Mean & Range & Mean & Range \\
\hline & $\begin{array}{l}\text { Comfortable making decisions for appropriate anaesthesia for specific } \\
\text { obstetric emergency }\end{array}$ & 3.68 & $1-5$ & 3.58 & $2-5$ \\
\hline & $\begin{array}{l}\text { General anaesthesia with rapid sequence induction, intubation and } \\
\text { ventilation }\end{array}$ & 3.68 & $2-5$ & 3.53 & $2-5$ \\
\hline & General anaesthesia: inhalation agents & 3.63 & $2-5$ & 3.45 & $2-5$ \\
\hline & $\begin{array}{l}\text { Manage high spinal with respiratory arrest. (Complication of spinal } \\
\text { anaesthesia) }\end{array}$ & 3.62 & $1-5$ & 3.35 & $1-5$ \\
\hline & General anaesthesia: induction & 3.59 & $2-5$ & 3.40 & $2-5$ \\
\hline & Muscle relaxants and reversal & 3.57 & $2-5$ & 3.40 & $2-5$ \\
\hline & Regional anaesthesia: biers block & 3.42 & $1-5$ & 3.08 & $1-5$ \\
\hline & Regional anaesthesia: brachial block & 3.00 & $1-5$ & 2.57 & $1-5$ \\
\hline \multirow[t]{16}{*}{$O \& G$} & Overall mean score & 3.88 & & 3.51 & \\
\hline & Performing caesarian section & 4.15 & $3-5$ & 3.90 & $1-5$ \\
\hline & Management of antepartum haemorrhage & 4.10 & $3-5$ & 3.92 & $2-5$ \\
\hline & Managing eclampsia & 4.02 & $2-5$ & 3.85 & $2-5$ \\
\hline & Manual removal of placenta & 3.93 & $2-5$ & 3.80 & $1-5$ \\
\hline & Endometrial biopsy & 3.83 & $1-5$ & 3.45 & $1-5$ \\
\hline & Acute management of cord prolapse & 3.80 & $2-5$ & 3.38 & $2-5$ \\
\hline & Caesarean section for breech presentation & 3.78 & $2-5$ & 3.52 & $1-5$ \\
\hline & Performing a breech delivery & 3.67 & $2-5$ & 3.18 & $1-5$ \\
\hline & Caesarian section with complications: excessive bleeding & 3.47 & $2-5$ & 3.22 & $1-5$ \\
\hline & Manage shoulder dystocia & 3.45 & $1-5$ & 2.90 & $1-5$ \\
\hline & Caesarian section with complications: tear into lower segment & 3.37 & $1-5$ & 3.03 & $1-5$ \\
\hline & Mini laparotomy for tubal ligation & 3.33 & $1-5$ & 3.02 & $1-5$ \\
\hline & Laparotomy for ectopic pregnancy & 3.08 & $1-5$ & 2.73 & $1-5$ \\
\hline & Vacuum extraction/outlet forceps delivery & 3.07 & $1-5$ & 2.72 & $1-5$ \\
\hline & Obstetric ultrasound & 2.82 & $1-5$ & 2.70 & $1-5$ \\
\hline
\end{tabular}

domains present acutely to DHs. The possibility of incorporating specific teaching in these specialities should be explored. There is a need for paediatric ARV training, greater exposure to medico-legal issues, and extra training in obstetric ultrasonography. All interns need more exposure to general anaesthetics; labour ward exposure should be compulsory during obstetric training; and more theatre time should be spent in obstetrics and gynaecology.

COSMOs in DHs are expected to function with minimal support and supervision. This should stimulate debate on what should be included in undergraduate and internship training. Clearly, ongoing assessment of the internship programme will be required to ensure that it adequately prepares young doctors for independent practice.

\section{References}

1. Sein N, Tumbo J. Determinants of effective medical intern training at a training hospital in North West Province, South Africa. African Journal of Health Professions Education 2012;4(1):10-14. [http://dx.doi. org/10.7196/AJHPE.100]

2. Meintijes Y. The 2-year internship training. S Afr Med J 2003;93(5):336-337.

3. African National Congress. A National Plan for Health for South Africa. Johannesburg: ANC, 1994;31-2,79-80.

4. Reid SJ, Conco D. Monitoring the implementation of community service. In: Crisp N, Ntuli A, eds. South African Health Review 1999. Durban: Health Systems Trust, 2000. http://www.hst.org.za/uploads/files/ chapter17_99.pdf (accessed 29 August 2013).

5. Public Health Intervention Through Legislative Advocacy Programme. Two years of postgraduate vocational training for medical doctors proposal. PHILA legislative update. 1996;6. http://www.healthlink.org.za/pphc/ mandserv.htm (accessed 20 September 2013).
6. Maseka DN. The perceptions and experiences of community service doctors about compulsory community service at Shongwe Hospital, Mpumalanga Province, Republic of South Africa. Presented at the World Rural Health 2002 International Conference, Melbourne, 1 - 3 May 2002.

7. Reid S. Compulsory community service for doctors in South Africa - an evaluation of the first year. S Af Med J 2001:91(4):329-336.

8. Reid, S. An overview of the first two years of community service. Health Systems Trust Update 2000;57:6-7. http://www.hst.org.za/uploads/files/upd57.pdf (accessed 29 August 2013).

Nemutandani MS, Maluleke FR, Rudolph MI. Community service doctors in Limpopo province. S Afr Med 2006;96(3):180-182.

10. Prinsloo EAM. A two-year internship programme for South Africa. S Afr Fam Pract 2005;47(5):3

11. Van Niekerk JP. Internship and community service require revision. S Afr Med J 2012;102(8):638. [http:// dx.doi.org/10.7196/SAMJ.6094

2. Jaschinski J, De Villiers MR. Factors influencing the development of practical skills of interns working in regional hospitals of the Western Cape province of South Africa. S Afr Fam Pract 2008;50(1):70a-70d.

13. Statistics South Africa. Millennium development goals: South African Country Report, 2010. Pretoria StatsSA, 2011. http://www.statssa.gov.za/news_archive/Docs/MDGR_2010 (accessed 29 August 2013).

14. Lawn SD, Myer L, Bekker LG, Wood R. Burden of tuberculosis in an antiretroviral treatment programme in sub-Saharan Africa: Impact on treatment outcomes and implications for tuberculosis control. AIDS 2006;20(12):1605-1612. [http://dx.doi.org/10.1097/01.aids.0000238406.93249.cd]

15. Mogale RS, Burns KK, RichterS. Violenceagainst women in South Africa: Policyposition and recommendation Violence Against Women 2012;18(5):580-594. [http://dx.doi.org/10.1177/1077801212453430]

6. ReidS. CO Reid S. Community service for health professionals. In: Ijumba P, ed. South African Health Review 2002 Durban: Health Systems Trust, 2002. http://www.hst.org.za/sites/default/files/chapter8.pdf (accessed

7. Mathebula MP, Mhlanga E, Reid S, et al. Skills and Competencies of Interns and Community Service Doctors. Pretoria: DoH, 2001

18. Lamacraft G, Kenny PJ, Diedericks BJ, Joubert G. Training and experience of doctors administering obstetric anaesthesia in the Free State Level 1 and 2 Hospitals. South African Journal of Anaesthesia and Analgesia 2008;14(2):13-17.

9. Saving Mothers 2005-2007: Fourth Report on Confidential Enquiries into Maternal Deaths in South Africa. National Department of Health. http://www.doh.gov.za/docs/reports/2011/saving_b.pdf (accessed 21 September 2013)

Accepted 25 February 2013 